\title{
Comparison of Short-Term Surgical Outcomes after Single-Incision Laparoscopic versus Multiport Laparoscopic Right Colectomy: A Two-Center, Prospective Case-Controlled Study of 100 Patients
}

\author{
Simone Velthuis ${ }^{a}$ Peter B. van den Boezem ${ }^{a}$ Daan J. Lips ${ }^{b}$ Hubert A. Prins ${ }^{b}$ \\ Miguel A. Cuestac ${ }^{c}$ Colin Sietses $^{a}$ \\ ${ }^{a}$ Department of Surgery, Gelderse Vallei Hospital, Ede, ${ }^{b}$ Department of Surgery, Jeroen Bosch Hospital, \\ 's-Hertogenbosch, and ' Department of Surgery, Vrije Universiteit Medical Center, Amsterdam, The Netherlands
}

\begin{abstract}
Key Words
Minimally invasive surgery $\cdot$ Laparoscopic surgery $\cdot$ Single incision $\cdot$ Single port $\cdot$ Colorectal cancer $\cdot$ Right colectomy
\end{abstract}

\begin{abstract}
Background: Recent case studies have demonstrated the feasibility of single-incision laparoscopic colectomy (SILC). Few comparative studies for SILC and multiport laparoscopic colectomy (MLC) have been conducted. The aim of this case-controlled study was to compare the short-term surgical outcomes between SILC and MLC for right-sided colectomies. Methods: Between January 2010 and February 2012, data from the first 50 consecutive patients that underwent right SILS at one of the two institutions were compared with a group of 50 consecutive patients that underwent right MLC in the same period. Results: Median operative time was significantly shorter in SILC (97 vs. 112 min; $p<0.001$ ). Between both groups, no statistically significant differences were found regarding number and nature of short-term complications, number of reoperations [4 (8\%) vs. $6(12 \%)]$, and mortality rate [1 (2\%) vs. $2(4 \%)]$. Median postoperative hospital stay was 6 days for both groups. Conclusion: SILC is a safe and feasible procedure when performed by experienced laparoscopic surgeons. Length of hospital stay and overall
\end{abstract}

complication rates are comparable with MLC. Until today, no clear advantages of SILC over MLC have been demonstrated. However, due to its smaller incisional trauma, SILC could be a major step in improving cosmetic outcomes.

Copyright $\odot 2012$ S. Karger AG, Basel

\section{Introduction}

Laparoscopic surgery is the standard therapy for a wide range of colonic diseases. Several randomized trials have clearly demonstrated its benefits compared to open surgery in short-term outcomes. These advantages included improved pain management, faster recovery of bowel function, reduced wound-related complications, shorter hospital admission, and improved cosmetic results [1-10]. Long-term outcomes proved to be equal to open surgery, some studies even suggesting better oncological results [10, 11].

To further reduce both incisional trauma and postoperative pain, single-incision laparoscopic surgery was introduced in the 1990s. This type of surgery permits operations to be performed entirely through one extraction site, generally through an umbilical incision [12].

\section{KARGER \\ Fax +4161306 1234}

E-Mail karger@karger.com

www.karger.com
C 2012 S. Karger AG, Basel

0253-4886/12/0296-0477\$38.00/0

Accessible online at:

www.karger.com/dsu
S. Velthuis, MD

Department of Surgery, Gelderse Vallei Hospital

Willy Brandtlaan 10, Postbus 9025

NL-6710 HN Ede (The Netherlands)

E-Mail velthuissimone@gmail.com 
Single-incision laparoscopic surgery was first applied to appendectomy and cholecystectomy. Even though it proved to be a save technique, most surgeons consider it a relatively difficult approach $[13,14]$. For that reason, its application to more advanced surgery is still limited.

In 2008, Remzi et al. [15] described the first singleincision laparoscopic right colectomy (SILC) in humans. Ever since, various retrospective case studies have demonstrated the feasibility of the single-incision procedure in colorectal surgery $[10,15-22]$. In recent years, the experience with SILC has grown, and surprisingly most surgeons experienced in single-incision laparoscopic cholecystectomy consider SILC relatively easier to perform than single-incision laparoscopic cholecystectomy.

Despite these publications, the widespread acceptance of this procedure has been limited. Recurrent discussion topics are a potential prolonged learning curve, compromised exposure or visualization, increased operative time, and oncological outcome $[23,24]$.

The aim of this study was to compare the short-term surgical outcomes between right SILC and right multiport laparoscopic colectomy (MLC).

\section{Patients and Methods}

\section{Patient Selection}

Between January 2010 and February 2012, patients in whom a laparoscopic right colectomy was indicated either at Gelderse Vallei Hospital (Ede, The Netherlands) or Jeroen Bosch Hospital ('s-Hertogenbosch, The Netherlands) were given the possibility to either undergo surgery according to the single-incision or to the multiport laparoscopic approach. We compared the first 50 consecutive patients who underwent right SILC with a control group of 50 consecutive patients who underwent right MLC.

Both multiport and single-incision laparoscopic procedures were conducted or supervised by the same group of surgeons, 2 and 3 experienced laparoscopic surgeons at Gelderse Vallei hospital and Jeroen Bosch hospital, respectively.

All surgeons had performed at least 50 single-incision laparoscopic procedures before performing right SILC. Both benign and malignant surgery indications were included, including carcinomas which were preoperatively suspicious for T4 carcinomas on computerized tomography. Within this study period, no elective open colectomies were performed.

Prior to the start of the study, approval was obtained from the institutional review boards of both institutions. Both institutions applied perioperative care according to the Enhanced Recovery after Surgery protocol [25].

Patient data and outcomes for SILC and MLC were recorded in a prospective database and were subsequently compared to each other. Preoperative patient data comprised age, sex, body mass index (BMI), indication for surgery and the presence of previous abdominal surgery. As a measure of patient comorbidity, the American Society of Anesthesiologists (ASA) classification was included.

In the setting of malignancy, tumor staging was assessed and reported by the use of the TNM classification system (Union for International Cancer Control, Geneva, Switzerland). Furthermore, length of specimen, tumor size, margin status and number of lymph nodes harvested (as defined in the pathology report) were acquired. Operative time, defined as time from first skin incision to completion of closure, and conversion were also obtained. Ultimately, short-term postoperative outcomes were evaluated, including duration of hospital stay, complications, the number of reoperation and mortality rate.

Surgical Technique

The executed MLC technique was a standard three-port technique, earlier described by Veenhof et al. [26].

For right SILC, the patient is placed in the supine position and tilted to the left. The left side of the patient is the working area for the surgeon and the assistant, the latter holding the camera at the head of the patient. Following infiltration with bupivacaine $0.25 \%$, the umbilicus is thoroughly disinfected, everted and opened longitudinally with a $3-\mathrm{cm}$ incision through the skin and fascia. A wound protector is placed and the single-incision port is introduced. A pneumoperitoneum is created after insertion of the trocarts. A standard $10-\mathrm{mm} 30^{\circ}$ laparoscope is used, as well as a straight atraumatic grasper and a $5-\mathrm{mm}$ LigaSure (Covidien, Mansfield, Mass., USA). All procedures were performed using the SILS port by Covidien (Covidien, Mansfield, Mass., USA) or the TriPort by Olympus (Olympus, Hamburg, Germany). These flexible ports have, respectively, three and four access ports, which can be used for 5- and 12-mm trocars and a separate insufflation attachment, plus desufflation attachment with the TriPort. During dissection, the grasper and LigaSure device change ports to ensure the best angle.

The patient is first placed in reversed Trendelenburg position. The hepatic flexure is mobilized from medial to lateral by opening the omentum at the proximal colon transversum. Subsequently, the attachments and the lateral peritoneal reflexion of the flexure are divided. Hereafter, patient's position is changed to Trendelenburg, and the terminal ileum is lifted. An opening is made in the mesentery, and the small bowel is divided using endostaplers (Tri-Staple Technology, Covidien, Mansfield, Mass., USA). The dissection then occurs in a medial to lateral approach. The coecum is lifted, and the mesentery is divided up to the basis of the ileocoelic artery. The ileocoelic vessels are divided using LigaSure. The retroperitoneal plane is developed until the duodenum is identified. The lateral peritoneum is opened, and the mesentery is divided to the middle colic artery. After complete mobilization of the right colon, both ends of the bowel are grasped and both the port and the specimen are taken out. If necessary, the incision is enlarged to a maximum of $4.5 \mathrm{~cm}$ for the externalization of the colon. A hand-sutured side-to-side anastomosis is created using 3.0 PDS (Ethicon, Cincinnati, Ohio, USA). The umbilical fascia is closed using interrupted Vicryl sutures (Ethicon, Cincinnati, Ohio, USA), and the umbilicus is restored using Monocryl intracutaneous sutures (Ethicon, Cincinnati, Ohio, USA) [18]. 
Table 1. Patient demographics

\begin{tabular}{|c|c|c|c|}
\hline & \multicolumn{3}{|c|}{ Laparoscopic right colectomy (Jan 2010 to Feb 2012) } \\
\hline & SILC & MLC & $\mathrm{p}$ value \\
\hline Patients & 50 & 50 & \\
\hline Age, years & $73 \pm 13.2$ & $71 \pm 11.8$ & $0.369^{1}$ \\
\hline \multicolumn{4}{|l|}{ Gender } \\
\hline Male & $21(42.0)$ & $22(44.0)$ & $0.840^{2}$ \\
\hline Female & $29(58.0)$ & $28(56.0)$ & \\
\hline Median BMI & $25(20-32)$ & $25(20-36)$ & $0.170^{1}$ \\
\hline ASA score & & & $0.424^{2}$ \\
\hline $1-2$ & $40(80.0)$ & $43(86.0)$ & \\
\hline$>3$ & $10(20.0)$ & $7(14.0)$ & \\
\hline History of abdominal surgery & $11(22.0)$ & $15(30.0)$ & $0.362^{2}$ \\
\hline Surgical indications & & & $0.799^{2}$ \\
\hline Malignant disease & $41(82.0)$ & $40(80.0)$ & \\
\hline Ascending colon adenocarcinoma & 27 & 23 & \\
\hline Cecal adenocarcinoma & 14 & 17 & \\
\hline Benign disease & $9(18.0)$ & $10(20.0)$ & \\
\hline Right colon adenoma & 5 & 6 & \\
\hline Right colon polyp & 2 & 4 & \\
\hline Other & 2 & - & \\
\hline
\end{tabular}

Values for age are expressed as mean \pm SD. Figures in parentheses indicate percentages or range.

${ }^{1}$ Independent-samples $\mathrm{t}$ test. ${ }^{2} \chi^{2}$ test.

Statistical Analysis

Data were collected and statistically analyzed using SPSS v19.0 (SPSS Inc., Chicago, Ill., USA).

Numerical data are presented as means with standard deviations or as medians with ranges. Continuous variables (means, standard deviations, medians and ranges) were analyzed using the independent-samples $t$ test. Categorical (ordinal and nominal) variables were analyzed using the $\chi^{2}$ test or the Fisher's exact test. $p$ values were two tailed. Statistical significance was accepted for $p$ values of $<0.05$.

\section{Results}

From January 2010 to February 2012, a total of 50 patients underwent right SILC at one of the two participating institutions. This group was compared with 50 patients who were operated on during the same period using the multiport laparoscopic technique. Patient characteristics are depicted in table 1 . No significant differences were found between the study groups, including median BMI, ASA score, history of abdominal surgery and surgical indication. Surgery indications comprised right-sided colon carcinomas, adenomas, polyps, and Crohn's disease.

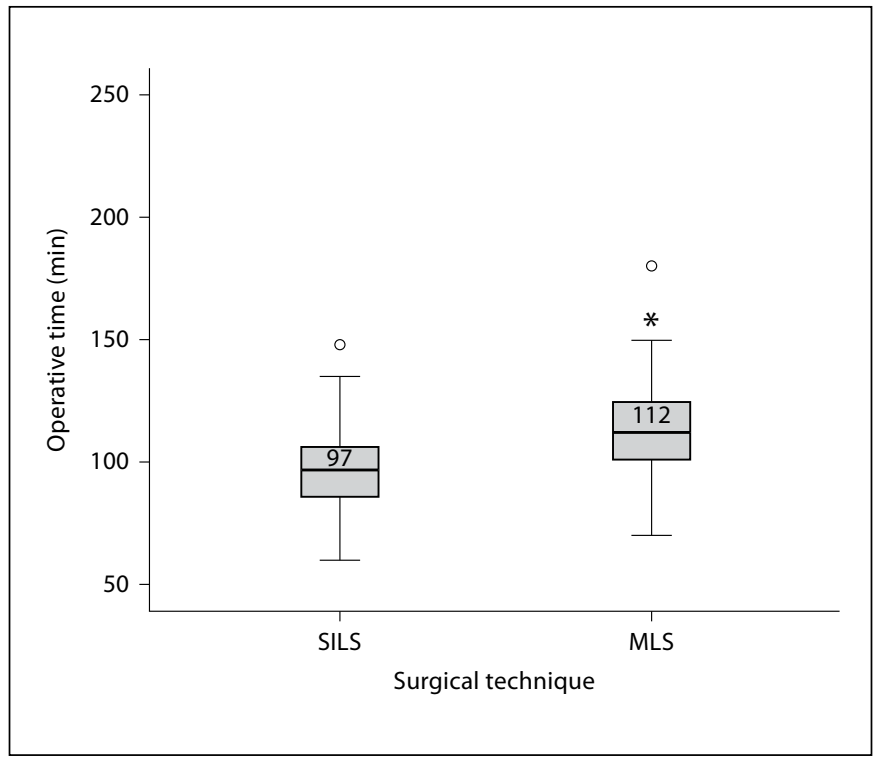

Fig. 1. Operative time according to surgical technique. The boxplots represent sample minimum, first quartile, median, third quartile, sample maximum, outliers (open circles), and maximum outlier (asterisk). 
Table 2. Data related to tumor pathology

\begin{tabular}{|c|c|c|c|}
\hline & \multicolumn{3}{|c|}{ Laparoscopic right colectomy } \\
\hline & $\operatorname{SILC}(n=41)$ & $\operatorname{MLC}(\mathrm{n}=40)$ & $\mathrm{p}$ value \\
\hline Length of specimen, $\mathrm{cm}$ & $26.13 \pm 6.9$ & $25.89 \pm 8.9$ & $0.883^{1}$ \\
\hline \multicolumn{4}{|l|}{ Histology type } \\
\hline Adenocarcinoma & $41(100)$ & $40(100)$ & $1.0^{2}$ \\
\hline Others & - & - & \\
\hline Largest tumor diameter, $\mathrm{cm}$ & $4.81 \pm 1.6$ & $4.64 \pm 1.8$ & $0.647^{1}$ \\
\hline Radical resection & $41(100)$ & $40(100)$ & $1.0^{2}$ \\
\hline Tumor depth (T classification) & & & $0.341^{2}$ \\
\hline $\mathrm{T} 1$ & $1(2.4)$ & $1(2.5)$ & \\
\hline $\mathrm{T} 2$ & $9(22.0)$ & $3(7.5)$ & \\
\hline T3 & $27(65.9)$ & $33(82.5)$ & \\
\hline $\mathrm{T} 4$ & $4(9.8)$ & $3(7.5)$ & \\
\hline Median harvested lymph nodes & $14.0(10-28)$ & $12.5(10-34)$ & $0.158^{1}$ \\
\hline Involved lymph nodes ( $\mathrm{N}$ classification) & & & $0.100^{2}$ \\
\hline N0 & $24(58.5)$ & $31(77.5)$ & \\
\hline N1 & $14(34.2)$ & $7(17.5)$ & \\
\hline N2 & $3(7.3)$ & $2(5.0)$ & \\
\hline
\end{tabular}

Values for length of specimen and largest tumor diameter are expressed as mean \pm SD. Figures in parentheses indicate percentages or range. T classification = Tumor staging according to TNM classification; N classification $=$ lymph node staging according to TNM classification.

${ }^{1}$ Independent-samples $t$ test. ${ }^{2} \chi^{2}$ test.

Statistical analysis showed a significant difference ( $\mathrm{p}<0.001)$ between SILC and MLC with respect to median operative time. As shown in figure 1, median operative time was 97 (60-148) min for SILC and 112 (70-225) min for MLC. Conversion to multiport laparoscopic surgery took place in 2 patients (4\%) of the SILC group because of severe adhesions. Neither in the SILC group, nor in the MLC group was conversion to open surgery necessary (see table 3 ). In all patients operated on for benign colon disease, the pathology report confirmed the benign preoperative surgery indication. All resections performed for malignancies had at least 10 lymph nodes harvested with a median of $14(10-28)$ nodes in the SILC group and 13 (10-34) nodes in the MLC group. The surgical resection margins were all tumor negative. For malignancies, the pathology reports mainly showed T2 or T3 tumors according to the TNM classification. As depicted in table 2 , malignant outcomes were statistically similar between groups.

No intraoperative complications were reported in either group.

Mortality was observed in both groups and comprised one postoperative death (age 89 with significant comorbidity) in the SILC group and two in the MLC group (age
74 and 88 , death due to a cerebrovascular accident and severe pneumosepsis). No significant differences were seen between groups for all postoperative outcomes, including mortality, reoperations, length of hospital stay and follow-up duration, as outlined in table 3. Anastomotic leak occurred in one SILC patient, compared to 3 patients in the MLC group (2 vs. 6\%). During follow-up, no port site hernias were observed in the SILC group, compared to $1(2 \%)$ in the MLC group. Indications for reoperation included postoperative bleeding, anastomotic leak, intra-abdominal abscess (unsuitable for percutaneous radiologic drainage), and fascial dehiscence. Median postoperative hospital stay was 6 days in both groups (range 2-41 for SILC and 2-103 for MLC). Median length of follow-up was 388 (58-772) days for SILC and 441 (69771) days for MLC.

\section{Discussion}

In recent years, a lot of research has been done to further reduce the impact of surgical trauma, resulting in new surgical techniques. By performing transgastric peritoneoscopies in porcine models, Kalloo et al. [27] 
Table 3. Intra- and postoperative outcomes

\begin{tabular}{llll}
\hline & \multicolumn{2}{l}{ Laparoscopic right hemicolectomy } & \\
\cline { 2 - 3 } & SILC $(\mathrm{n}=50)$ & MLC (n=50) & p value \\
\hline Intraoperative complications & - & & $0.495^{2}$ \\
Conversion rate & $2(4.0)$ & - & \\
To multiport laparoscopy & $2(4.0)$ & - & \\
To open method & - & - & $0.495^{1}$ \\
Postoperative complications & & & $0.617^{1}$ \\
Bleeding & - & $2(4.0)$ & $1.0^{1}$ \\
Anastomotic leak & $1(2.0)$ & $3(6.0)$ & $1.0^{1}$ \\
Intra-abdominal abscess & $2(4.0)$ & $1(2.0)$ & $1.0^{1}$ \\
Wound infection & $4(8.0)$ & $3(6.0)$ & $0.715^{1}$ \\
Fascial dehiscence & $1(2.0)$ & $1(2.0)$ & $1.0^{1}$ \\
Ileus/delayed bowel function & $5(10.0)$ & $3(6.0)$ & $0.617^{1}$ \\
Cardiovascular event & $1(2.0)$ & $1(2.0)$ & $1.0^{1}$ \\
Pneumonia & $3(6.0)$ & $1(2.0)$ & $1.0^{1}$ \\
Pulmonary embolism & - & $1(2.0)$ & $0.505^{2}$ \\
Port site hernia & - & $1(2.0)$ & $1.0^{1}$ \\
Reoperation & $4(8.0)$ & $6(12.0)$ & $0.343^{3}$ \\
Mortality & $1(2.0)$ & $2(4.0)$ & $0.251^{3}$ \\
Median postoperative hospital stay, days & $6(2-41)$ & $6(2-103)$ & \\
Median follow-up, days & $388(58-772)$ & $441(69-771)$ & \\
\hline
\end{tabular}

Figures in parentheses indicate percentages or range.

${ }^{1}$ Independent-samples $t$ test. ${ }^{2} \chi^{2}$ test. ${ }^{3}$ Fisher's exact test.

were regarded as the first to describe a natural orifice translumenal endoscopic surgery (NOTES) procedure. NOTES provides potential opportunities and could be the next logical step in performing laparoscopic surgery. However, the current associated technical problems of these procedures still leads to insufficient medical guaranteed safety, resulting in slow adoption of NOTES [28].

During the development of NOTES, the single-incision laparoscopy trocar was introduced as a new 'scarless' approach and considered as a spin-off of all NOTES-related research. One of the most important advantages of singleport laparoscopic surgery over NOTES is the possibility to use conventional laparoscopic instruments. This has currently led to an overall greater acceptance of singleincision laparoscopic surgery than NOTES [29-32].

Various studies proved single-incision cholecystectomy to be a safe and feasible procedure [32-35]. Operative time and complications seem to be comparable with normal laparoscopy [36] with a learning curve of around 1015 procedures [18, 37, 38]. Even though single-incision laparoscopic surgery could have benefits compared to conventional laparoscopic surgery, particularly regard- ing cosmetic results, there are some technical drawbacks associated with this type of surgery. Clashing of instruments externally at the umbilicus and crossing of instruments internally makes single-incision laparoscopic surgery a challenging procedure to perform, especially in cholecystectomy and appendectomy $[39,40]$.

We started performing SILC at the beginning of 2010, and as discussed earlier, we noticed that SILC was easier to perform than single-incision laparoscopic cholecystectomy. In our opinion, this is the result of a greater area of dissection with SILC compared to single-incision laparoscopic cholecystectomy. During dissection of the hilus in cholecystectomy, the tips of the instruments are close together, causing clashing of instruments outside the trocar. In the case of a greater operation area, the tips are wider apart, which reduces clashing of the instruments outside the trocar.

Having performed several successful right SILC operations, we moved to more complex colonic procedures. Currently, at our institutions, most colorectal procedures are performed through single-incision laparoscopy. However, as we are teaching hospitals, still a lot of multiport procedures are done, mainly by senior residents. 
In this article, we describe the first 50 right SILC procedures, performed in two high-volume colorectal units in the Netherlands, and compare these data to a group of 50 multiport laparoscopic right colectomies.

No significant differences were seen between the two groups, except for the operative time, which was shorter in the SILC approach. An explanation for this finding is that multiport laparoscopic procedures are frequently carried out by residents, in contrast to single-incision laparoscopic procedures, which are only performed by experienced laparoscopic surgeons. Although calculations show a statistically significant difference between operative times, these differences are not clinically relevant. Nevertheless, SILC appears to have acceptable operative times, which in experienced hands are comparable to MLC, as proven in other studies [16, 22]. Our results show a similar number and nature of complications after right SILC and right MLC.

A recent multicenter, case-controlled trial by Champagne et al. [16] compared general SILC to MLC in a total of 330 patients ( 165 vs. 165), from which 234 operations (71\%) involved right colectomies, with a similar distribution between SILC and MLC ( $\mathrm{p}=1.0)$. Comparable to our results, no statistically significant differences were found regarding length of hospital stay, number of reoperations, and number and nature of short-term complications. In contrast to our results, however, they found similar mean operative times of around $135 \mathrm{~min}$ between the two groups. Nevertheless, these operative times also include, for instance, left colectomies, proctectomies, and total colectomies, resulting in less reliable comparison between their and our study group.

In another recent study conducted by Adair et al. [22], 17 patients who underwent right SILC were compared with case-matched right MLC. They measured a mean operative time of $139 \mathrm{~min}$ in right SILC and $134 \mathrm{~min}$ in right MLC, and similar short-term complications across both groups.

Currently, no large randomized controlled trials or case-control studies are available to determine long-term (oncological) outcomes, port site complications, and costs. Comparable to our study, several trials concluded that single-port laparoscopic surgery is a safe and feasible surgery technique. However, no additional benefits related to this surgery technique have yet been demonstrated. Theoretically, it will be more appealing to patients because of better cosmetic results, compared to multiport laparoscopic surgery [10, 15-22].

Our research group recently sent questionnaires, including body image questionnaires, to female patients af- ter having a cholecystectomy through a multiport or single-incision laparoscopic, or hybrid transvaginal approach. The results showed a strong prevalence for single-port laparoscopic and transvaginal cholecystectomy. Whether this cosmetic advantage is relevant in patients operated on for cancer remains unclear, and should be reflected in future studies.

Another future discussion point is the implementation of the single-incision laparoscopic surgery technique in the surgical training of residents. Our residents start with multiport laparoscopic surgery and progress to single-incision laparoscopic procedures.

In conclusion, single-incision laparoscopic surgery is a safe and feasible procedure when performed by experienced laparoscopic surgeons. Length of hospital stay and overall complication rates are comparable with multiport laparoscopic surgery. Whether the suspected reduction in surgical trauma will result in clinically relevant benefits remains to be proven. Single-incision laparoscopic surgery could be a major step in improving cosmetic outcomes and could therefore potentially increase overall postoperative patient satisfaction.

\section{Disclosure Statement}

Simone Velthuis, Peter B. van den Boezem, Daan J. Lips, Hubert A. Prins, Miguel A. Cuesta, and Colin Sietses have no conflicts of interest or financial ties to disclose.

References

1 Wexner SD, Reissman P, Pfeifer J, Bernstein $\mathrm{M}$, Geron N: Laparoscopic colorectal surgery: analysis of 140 cases. Surg Endosc 1996; 10:133-136.

2 Okabayashi K, Hasegawa $\mathrm{H}$, Watanabe M, Nishibori H, Ishii Y, Hibi T, Kitajima M: Indications for laparoscopic surgery for Crohn's disease using the Vienna classification. Colorectal Dis 2007;9:825-829.

-3 Hildebrandt U, Kessler K, Plusczyk T, Pistorius G, Vollmar B, Menger MD: Comparison of surgical stress between laparoscopic and open colonic resections. Surg Endosc 2003; 17:242-246.

-4 Bonjer HJ, Hop WC, Nelson H, Sargent DJ, Lacy AM, Castells A, Guillou PJ, Thorpe H, Brown J, Delgado S, Kuhrij E, Haglind E, Pahlman L, Transatlantic Laparoscopically Assisted vs Open Colectomy Trials Study G: Laparoscopically assisted vs open colectomy for colon cancer: a meta-analysis. Arch Surg (Chicago) 2007;142:298-303. 
5 Clinical Outcomes of Surgical Therapy Study G: A comparison of laparoscopically assisted and open colectomy for colon cancer. N Engl J Med 2004;350:2050-2059.

-6 Milsom JW, Bohm B, Hammerhofer KA, 18 Fazio V, Steiger E, Elson P: A prospective, randomized trial comparing laparoscopic versus conventional techniques in colorectal cancer surgery: a preliminary report. J Am Coll Surg 1998;187:46-54, discussion 54-45.

7 Braga M, Vignali A, Gianotti L, Zuliani W, Radaelli G, Gruarin P, Dellabona P, Di Carlo V: Laparoscopic versus open colorectal surgery: a randomized trial on short-term outcome. Ann Surg 2002;236:759-766, discussion 767.

-8 Jayne DG, Guillou PJ, Thorpe H, Quirke P, Copeland J, Smith AM, Heath RM, Brown JM, Group UMCT: Randomized trial of laparoscopic-assisted resection of colorectal carcinoma: 3-year results of the UK MRC CLASICC trial group. J Clin Oncol 2007;25: 3061-3068.

-9 Veldkamp R, Kuhry E, Hop WC, Jeekel J, Kazemier G, Bonjer HJ, Haglind E, Pahlman L, Cuesta MA, Msika S, Morino M, Lacy AM, Group COcLoORS: Laparoscopic surgery versus open surgery for colon cancer: shortterm outcomes of a randomised trial. Lancet Oncol 2005;6:477-484.

$>10$ Kim SJ, Ryu GO, Choi BJ, Kim JG, Lee KJ, Lee SC, Oh ST: The short-term outcomes of conventional and single-port laparoscopic surgery for colorectal cancer. Ann Surg 2011; 254:933-940.

-11 Lacy AM, Garcia-Valdecasas JC, Delgado S, Castells A, Taura P, Pique JM, Visa J: Laparoscopy-assisted colectomy versus open colectomy for treatment of non-metastatic colon cancer: a randomised trial. Lancet 2002; 359:2224-2229.

12 Piskun G, Rajpal S: Transumbilical laparoscopic cholecystectomy utilizes no incisions outside the umbilicus. J Laparoendosc Adv Surg Tech A 1999;9:361-364.

13 Inoue H, Takeshita K, Endo M: Single-port laparoscopy assisted appendectomy under local pneumoperitoneum condition. Surg Endosc 1994;8:714-716.

14 Navarra G, Pozza E, Occhionorelli S, Carcoforo P, Donini I: One-wound laparoscopic cholecystectomy. Br J Surg 1997;84:695.

15 Remzi FH, Kirat HT, Kaouk JH, Geisler DP: Single-port laparoscopy in colorectal surgery. Colorectal Dis 2008;10:823-826.

16 Champagne BJ, Papaconstantinou HT, Parmar SS, Nagle DA, Young-Fadok TM, Lee EC, Delaney CP: Single-incision versus standard multiport laparoscopic colectomy: a multicenter, case-controlled comparison. Ann Surg 2012;255:66-69.
17 Makino T, Milsom JW, Lee SW: Feasibility and safety of single-incision laparoscopic colectomy: a systematic review. Ann Surg 2012;255:667-676.

18 van den Boezem PB, Sietses C: Single-incision laparoscopic colorectal surgery, experience with 50 consecutive cases. J Gastrointest Surg 2011;15:1989-1994.

19 Chen WT, Chang SC, Chiang HC, Lo WY, Jeng LB, Wu C, Ke TW: Single-incision laparoscopic versus conventional laparoscopic right hemicolectomy: a comparison of shortterm surgical results. Surg Endosc 2011;25: 1887-1892.

20 Leblanc F, Champagne BJ, Augestad KM, Stein SL, Marderstein E, Reynolds HL, Delaney CP: Single incision laparoscopic colectomy: technical aspects, feasibility, and expected benefits. Diagn Ther Endosc 2010; 2010:913216.

21 Bucher P, Pugin F, Morel P: Single port access laparoscopic right hemicolectomy. Int J Colorect Dis 2008;23:1013-1016.

22 Adair J, Gromski MA, Lim RB, Nagle D: Single-incision laparoscopic right colectomy: experience with 17 consecutive cases and comparison with multiport laparoscopic right colectomy. Dis Colon Rectum 2010;53: 1549-1554.

23 Tekkis PP, Senagore AJ, Delaney CP, Fazio $\mathrm{VW}$ : Evaluation of the learning curve in laparoscopic colorectal surgery: comparison of right-sided and left-sided resections. Ann Surg 2005;242:83-91.

-24 Waters JA, Guzman MJ, Fajardo AD, Selzer DJ, Wiebke EA, Robb BW, George VV: Single-port laparoscopic right hemicolectomy: a safe alternative to conventional laparoscopy. Dis Colon Rectum 2010;53:1467-1472.

25 Kehlet H, Wilmore DW: Evidence-based surgical care and the evolution of fast-track surgery. Ann Surg 2008;248:189-198.

26 Veenhof AA, Van Der Pas MH, Van Der Peet DL, Bonjer HJ, Meijerink WJ, Cuesta MA, Engel AF: Laparoscopic versus transverse incision right colectomy for colon carcinoma. Colorectal Dis, DOI: 10.1111/j.1463-1318.2010.02413.x.

27 Kalloo AN, Singh VK, Jagannath SB, Niiyama H, Hill SL, Vaughn CA, Magee CA, Kantsevoy SV: Flexible transgastric peritoneoscopy: a novel approach to diagnostic and therapeutic interventions in the peritoneal cavity. Gastrointest Endosc 2004;60:114117.

28 Maiss J, Zopf Y, Hahn EG: Entrance barriers and integration obstacles of notes. Minim Invasive Ther Allied Technol 2010;19:287291.
29 Chamberlain RS, Sakpal SV: A comprehensive review of single-incision laparoscopic surgery (SILS) and natural orifice transluminal endoscopic surgery (notes) techniques for cholecystectomy. J Gastrointest Surg 2009;13:1733-1740.

30 Chow A, Purkayastha S, Aziz O, Pefanis D, Paraskeva P: Single-incision laparoscopic surgery for cholecystectomy: a retrospective comparison with 4-port laparoscopic cholecystectomy. Arch Surg (Chicago) 2010;145: 1187-1191.

31 Kehagias I, Karamanakos SN, Markopoulos GA, Kalfarentzos F: Benefits and drawbacks of SILS cholecystectomy: a report of 60 SILS cholecystectomies with conventional instrumentation from an academic center. Surg Innov 2012;19:438-445.

-32 Rivas H, Varela E, Scott D: Single-incision laparoscopic cholecystectomy: initial evaluation of a large series of patients. Surg Endosc 2010;24:1403-1412.

-33 Erbella J Jr, Bunch GM: Single-incision laparoscopic cholecystectomy: the first 100 outpatients. Surg Endosc 2010;24:1958-1961.

34 Roberts KE, Solomon D, Duffy AJ, Bell RL: Single-incision laparoscopic cholecystectomy: a surgeon's initial experience with 56 consecutive cases and a review of the literature. J Gastrointest Surg 2010;14:506-510.

35 Cuesta MA, Berends F, Veenhof AA: The invisible cholecystectomy': a transumbilical laparoscopic operation without a scar. Surg Endosc 2008;22:1211-1213.

- 36 Pollard JS, Fung AK, Ahmed I: Are natural orifice transluminal endoscopic surgery and single-incision surgery viable techniques for cholecystectomy? J Laparoendosc Adv Surg Tech A 2012;22:1-14.

37 Solomon D, Bell RL, Duffy AJ, Roberts KE: Single-port cholecystectomy: small scar, short learning curve. Surg Endosc 2010;24: 2954-2957.

38 Kehagias I, Karamanakos SN, Markopoulos GA, Kalfarentzos F: Benefits and drawbacks of SILS cholecystectomy: a report of 60 SILS cholecystectomies with conventional instrumentation from an academic center. Surg Innov 2012;19:438-445.

- 39 Miernik A, Schoenthaler M, Lilienthal K, Frankenschmidt A, Karcz WK, Kuesters S: Pre-bent instruments used in single-port laparoscopic surgery versus conventional laparoscopic surgery: comparative study of performance in a dry lab. Surg Endosc 2012; 26:1924-1930.

40 Tang B, Hou S, Cuschieri SA: Ergonomics of and technologies for single-port laparoscopic surgery. Minim Invasive Ther Allied Technol 2012;21:46-54.
Single-Incision Laparoscopic vs. Multiport Laparoscopic Right Colectomy 